Int. J. Electrochem. Sci., 11 (2016) 2550 - 2559

\title{
Anthraquinone Immobilized on Reduced Graphene Oxide Sheets with Improved Electrochemical Properties for Supercapacitors
}

\author{
Jianli Ren, Xin Zhao*, Junxian Zhang, and Qinghua Zhang* \\ College of Materials Science \& Engineering, State Key Laboratory for Modification of Chemical \\ Fibers and Polymer Materials, Donghua University, Shanghai 201620, China \\ *E-mail: xzhao@dhu.edu.cn, qhzhang@dhu.edu.cn
}

doi: $10.20964 / 110402550$

Received: 22 December 2015 / Accepted: 7 February 2016 / Published: 1 March 2016

\begin{abstract}
Organic compounds have attracted attention as inexpensive and environmentally friendly active materials for energy storage devices. To overcome their poor electrical conductivity and dissolublility in the electrolyte, the construction of electric conductive network to hold the organic molecules is necessary. Here, we selected reduced graphene oxide sheets as the conductive substrate and used hydrothermal reaction to immobilize 1,5-diaminoanthraquinone molecules on the graphene backbone. The obtained composite showed an improved specific capacitance with a specific capacitance of 277 $\mathrm{F} / \mathrm{g}$ at scan rate of $5 \mathrm{mV} / \mathrm{s}$, which was much larger than that of the pristine DAA $(7.5 \mathrm{~F} / \mathrm{g})$ and RGO $(63.3 \mathrm{~F} / \mathrm{g})$. Moreover, it also possessed a good cycling stability with a retention of $96.6 \%$ after 1000 cycles. The improved electrochemical behaviors of the composites are due to the conductive pathway of graphene and the positive synergistic effects between two components, indicating a great potential as electrodes for supercapacitors.
\end{abstract}

Keywords: anthraquinone, graphene oxide, electrochemical, supercapacitors

\section{$\underline{\text { FULL TEXT }}$}

(C) 2016 The Authors. Published by ESG (www.electrochemsci.org). This article is an open access article distributed under the terms and conditions of the Creative Commons Attribution license (http://creativecommons.org/licenses/by/4.0/). 